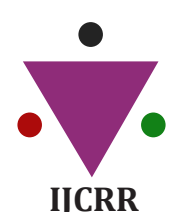

IJCRR

Section: Healthcare

Sci. Journal Impact

Factor: 6.1 (2018)

ICV: 90.90 (2018)

(c) (5) (8)

Copyright@IJCRR

\section{Computational Screening of Drug-like Properties of Tinospora Cordifolia Against Tuberculosis}

\section{Shivangi Solanki ${ }^{1}$, Devvret Verma ${ }^{1}$, Rishabh Solanki ${ }^{1}$, Kumud Pant ${ }^{1}$, Bhasker Pant ${ }^{3}$, Vikas Tripathi' ${ }^{3}$, Ashish Thapliyal²}

\author{
'Department of Biotechnology, Graphic Era Deemed to be University, Dehradun, Uttarakhand, India; ${ }^{2}$ Department of Life Sciences, \\ Graphic Era Deemed to be University, Dehradun, Uttarakhand, India; ${ }^{3}$ Computer Science Department, Graphic Era Deemed to be Univer- \\ sity, Dehradun, Uttarakhand, India.
}

\title{
ABSTRACT
}

Background: Drug-Resistant Tuberculosis (TB) resurrection over the globe broadens the research towards its causative agent Mycobacterium tuberculosis. The diarylquinoline derivative drug Bedaquiline which inhibits ubiquitous enzyme ATP synthase was introduced in 2012. ATP synthase is an essential enzyme that helps in supplying energy to Mycobacterium tuberculosis even in the unfavourable conditions which helps them to survive in macrophages of human beings. Since 2017, resistance to bedaquiline has been reported worldwide which emphases us for the discovery of the new drugs. The medicinal plant Tinospora cordifolia is used in various traditional healing systems worldwide to treat diabetes, leprosy, etc.

Methods: The current study summarizes the pharmacology of the phytocompounds of Tinospora cordifolia. In silico study was performed by using tools like CASTp, PubChem, ChemSpider, Swiss ADME, Pro Tox server, HEX dock, PyMol, and Lig plot+. ADMET study of the phytocompounds was also studied.

Results: The results obtained in the study indicated that the 2-Hydroxy-3-oxoicosanoate was the potent inhibitor which shows the highest affection towards ATP synthase of Mycobacterium tuberculosis and also accomplishes the entire criterion to be an effective drug.

Conclusions: Many of the phytocompounds of Tinospora cordifolia shows good ADMET analysis and docking result. Among all the phytocompounds 2-Hydroxy-3-oxoicosanoate shows the best result in terms of docking. This is only an in-silico study to fasten the drug discovery process, further validation of the proposed drug requires in-vitro and in-vivo study.

Key Words: ADMET, Docking Study, Mycobacterium tuberculosis, Tinospora cordifolia, Tuberculosis, 2-Hydroxy-3-oxoicosanoate

\section{INTRODUCTION}

Mycobacterium tuberculosis (Mtb) bacteria are always being a challenge due to its resistance property towards the firstline drugs i.e. isonicotinic acid hydrazide (INH), Rimactane, ethambutol, and pyrazinamide, the condition is known as Multi-Drug Resistant (MDR) TB. In the worst case, it can lead to Extensive Drug Resistance (XDR) TB i.e. resistance to any fluoroquinolone drugs. ${ }^{1}$ In the year 1993, the worldwide health crisis has been affirmed by the WHO (World Health Organisation) when 1.3-1.6 million deaths were estimated each year from tuberculosis1. Recently in 2014 WHO and United Nations (UN) launched the "End TB Strategy" at the World Health Assembly by adopting UN Sustainable Development Goals in 2015. ${ }^{2}$ The present-day scenario of
TB states that the drugs available in the market are ineffectual against TB as there exist around 2.3 million cases of TB around the globe. ${ }^{2}$ After the rigorous clinical trials for new drugs against drug resistance TB, Bedaquiline (Sirturo) came in the market with a new hope. It is a diarylquinoline offshoot which inhibits the $\varepsilon$ subunit of mycobacterium adenosine triphosphate (ATP) synthase. ${ }^{3}$ ATP synthase is a ubiquitous enzyme in which theatre crucial functions in chemiosmotic energy change. Mtb is astute enough that it escapes the primary defence mechanism of the host, and deals with hostile conditions within the macrophages. ATP synthase is responsible for optimal development and metabolism in Mtb. ATP synthase enzyme utilizes the power store in a transmembrane for the making of ATP. ATP synthase has two parts hydrophilic F1 complex which has 5 subunits

\section{Corresponding Author:}

Devvret Verma, Department of Biotechnology, Graphic Era Deemed to be University, Dehradun, Uttarakhand, India; Email: devvret@gmail.com

ISSN: 2231-2196 (Print)

Received: 13.08 .2020
ISSN: 0975-5241 (Online)

Revised: 17.09 .2020
Accepted: 12.10 .2020 
$\alpha 3 \beta 3 \gamma \delta \varepsilon$ and membrane entrenched F0 complex which has 3 subunits a1 b2 c10-15. ${ }^{4}$ The World Health Organization (WHO) said that the inappropriate utilize of bedaquiline can lead to the resistance and according to the current status the mutation in the AtpE gene of Mtb has been noticed in many cases which results in bedaquiline resistance and research is aimed to ascertain a new suitable inhibitor of ATP synthase. ${ }^{5}$ Medicinal plants and marine species have been in use for epochs to cure tuberculosis. ${ }^{6}$ Tinospora cordifolia is a deciduous climbing shrub known as "Guduchi" belonging to the family Menispermaceae which is found at higher altitudes. ${ }^{7}$ It has anti-diabetic antiperiodic, antispasmodic, and anti-inflammatory properties. The plant generally contains alkaloids, glycosides, steroids, and aliphatic compounds. ${ }^{8}$ According to the survey, there is a rapid increase in TB cases which suggests the development of an effective treatment. ATP synthase can serve as a probable target for drug and Tinospora cordifolia has been reported to be an effective medicinal plant. The amalgamation of these two factors aggravated us towards the in-silico study of phytocompounds of Tinospora cordifolia in computer-aided drug designing, which is expected to assist in craft a new antitubercular drug. In the current study, the phytocompounds of Tinospora cordifolia was used as a ligand molecule against TB. The ADMET properties of phytocompounds were predicted for assessing efficiency, inhibition capacity, absorption, distribution, metabolism, and toxicity response of drugs.

\section{MATERIAL AND METHODS}

\section{Target and Cavity Prediction}

3D structure file of Mtb F-ATP synthase subunit epsilon (ATPE) (PDB file: 5YIO) was retrieved from Protein Database (PDB) (https://www.rcsb.org). ${ }^{9} 5 \mathrm{YIO}$ is an NMR determined structure. ${ }^{10}$ CASTp (Computed Atlas of Surface Topography of proteins) is an online source that makes available the detailed quantitative analysis of voids and pockets of proteins present on the surface which are often allied with protein binding sides. It is used for ascertaining surface features and functional regions of proteins. Access to CASTp is four-letter PDB file (http://sts.bioe.uic.edu). ${ }^{11}$

\section{Ligand Preparation}

The phytocompounds of Tinospora cordifolia were retrieved from the chemical structure databases: PubChem and ChemSpider. PubChem database gives information about chemical substances and their biological activities. It has three interlinked databases i.e. compound, substance, and bioassays (https://pubchem.ncbi.nlm.nih.gov/). ${ }^{12}$ ChemSpider is a chemical database offering access to properties of a compound like its physiochemical properties, 2D, and $3 \mathrm{D}$ structure (http://www.chemspider.com/ $/)^{13}$. The configuration of the compounds was taken from both the data bank and transformed to .pdb format by Open Babel tool version 2.4.1. It is an online toolbox that can verbalize many languages of the chemical data and can convert it in a user suitable form ${ }^{14}$.

\section{ADMET prediction}

ADMET prediction is indispensable to know whether the ligand can be taken via the oral route by human beings. Insilico ADMET predictions of the ligands were done by using the SwissADME predictor and ProTox-II. Swiss ADME is a web tool that assesses a compound on the analysis of its absorption, distribution, metabolism, and excretion (ADME). It is free to access to a predictive model of a compound to be a potent drug(http://www.swissadme.ch) ${ }^{15}$. ProTox-II is an online net server for the in-silico toxicity calculation of compounds (http://tox.charite.de) ${ }^{16}$. The ADMET analyses of the compounds were done and the best compounds which passed ADMET analyses were taken further for molecular docking. The diagnosis of phytocompounds was done based on their chemistry analysis, Molar Refractivity, TPSA, Lipophilicity, Consensus Log Po/w, GI absorption, BBB permeant, P-gp substrate, Lipinski, Bioavailability Score.

\section{Docking}

Mycobacterium tuberculosis F-ATP synthase subunit epsilon (ATPE) (PDB file: 5YIO.A) was docked with different ligands using Hex 8.0.0. Hex is a docking software that works in the FFT algorithm (Fast Fourier transform) and docking energy was tabulated using the default parameters ${ }^{17}$. Docking visualization was done with the help of PyMol and Lig Plot+. PyMol is a molecular visualization tool that works in horizontal and vertical scripts. It shows the $3 \mathrm{D}$ visualization of a compound ${ }^{18}$. Ligplot + is also visualization software that shows the intermolecular attraction, hydrogen bonding, and hydrophobic interactions ${ }^{19}$.

\section{RESULT AND DISCUSSION}

\section{Cavity prediction and Ligand preparation}

Structural pockets and cavities determine the binding sites and active sites of the protein. CASTp server is an online service that works by using the alpha complex, Delaunay triangulation, and default probe sphere 1. $4 \AA$. PDB file of Mtb F-ATP synthase subunit epsilon (ATP $\varepsilon$ ), 5YIO_A was uploaded to the CASTp server which isolates and measures the surface pockets and cavities. The results of CASTp calculation show the presence of one large pocket. The volume and Area of solvent accessible surface (SA) of pocket and the corresponding amino acid was shown in Table 1. In the current study chemical structure databases, ChemSpider and PubChem were used to retrieve the $2 \mathrm{D}$ and $3 \mathrm{D}$ structure of all the phytocompounds present in Tinospora cordifolia. The structures were downloaded and transformed into .pdb layout by Open Babel tool version 2.4.1 (figure 1). 


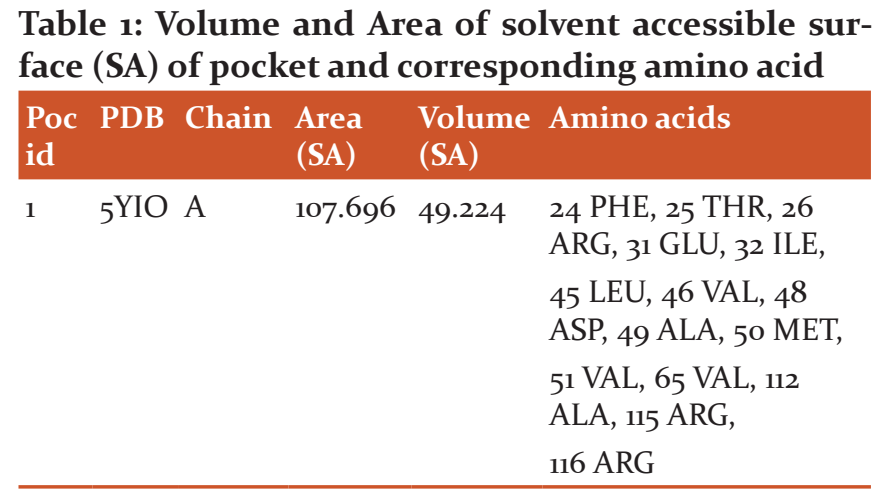

\section{ADMET analysis and Docking}

In advance of launching a drug to the market it faces several clinical trials. ADMET analysis is an indispensable phase of pharmacokinetics that provides substantial information about the drug's ability of a compound. Swiss ADME and ProTox-II were used for ADMET analysis of the phytocompounds. Phytocompounds meeting all the values of the ADMET analysis are shown in Tables 2 and 3. Swiss ADME analyzes the physicochemical (PC) properties of the phytocompounds.

Table 2: ADMET analysis of the phytocompounds

\begin{tabular}{|c|c|c|c|c|c|c|c|c|}
\hline CID & Compound & ESOL & Ali Class & SIT Class & BBB & Pgp S & CI & Tox \\
\hline 192176 & Cholic acid & SOL & SOL & SOL & $\mathrm{NO}$ & YES & NO & Predicted LD5o: $2000 \mathrm{mg} / \mathrm{kg}$ \\
\hline 85597 & Diffractaic acid & M SOL & P SOL & M SOL & $\mathrm{NO}$ & $\mathrm{NO}$ & $\mathrm{NO}$ & Predicted LD50: 300mg/kg \\
\hline 4316406 & $\begin{array}{l}\text { 3,3-Bis }(3,4 \text {-dimethoxyphenyl) } \\
\text { propanoate }\end{array}$ & SOL & M SOL & M SOL & $\mathrm{NO}$ & NO & $\mathrm{NO}$ & $\begin{array}{l}\text { Predicted } \\
\text { LD50: } 1300 \mathrm{mg} / \mathrm{kg}\end{array}$ \\
\hline 5320699 & 3-(1-Naphthoyl)benzoate & M SOL & M SOL & M SOL & YES & $\mathrm{NO}$ & NO & Predicted LD5o: 200mg/kg \\
\hline 13902409 & 2-Hydroxy-3-oxoicosanoate & M SOL & P SOL & M SOL & $\mathrm{NO}$ & YES & NO & Predicted LD50: $3400 \mathrm{mg} / \mathrm{kg}$ \\
\hline 5461627 & $\begin{array}{l}\text { (4-Cinnamoyl-3,5-dihydroxy- } \\
\text { phenoxy)acetate }\end{array}$ & SOL & M SOL & SOL & $\mathrm{NO}$ & NO & NO & Predicted LD5o: $3800 \mathrm{mg} / \mathrm{kg}$ \\
\hline
\end{tabular}

*CID: PubChem Compound ID, Sol: Soluble, M Sol : Moderately Sol, P Sol: Poorly Soluble, SIT Class: Silicos-IT class, BBB: Blood Brain Barrier permeant, Pgp S: Pgp substrate, CI: CYP3 $\mathrm{A}_{4}$ inhibitor, Tox: Toxicity

Table 3: Computed properties of screened compounds based on Lipinski's Rule of Five

\begin{tabular}{|c|c|c|c|c|c|c|}
\hline Phytocompound Name & Formula & MW & $\begin{array}{l}\text { \#H-bond } \\
\text { acceptors }\end{array}$ & $\begin{array}{l}\text { \#H-bond } \\
\text { donors }\end{array}$ & $\begin{array}{l}\text { Lipinski \#vio- } \\
\text { lations }\end{array}$ & MLOGP \\
\hline Cholic acid & $\mathrm{C}_{24} \mathrm{H}_{4} \mathrm{OO}_{5}$ & $408.57 \mathrm{~g} / \mathrm{mol}$ & 5 & 4 & Yes; o violation & 3.05 \\
\hline Diffractaic acid & $\mathrm{C}_{2} \mathrm{OH}_{22} \mathrm{O}_{7}$ & $374.38 \mathrm{~g} / \mathrm{mol}$ & 7 & 2 & Yes; o violation & 2.76 \\
\hline $\begin{array}{l}\text { 3,3-Bis(3,4-dimethoxyphenyl)pro- } \\
\text { panoate }\end{array}$ & $\mathrm{C}_{19} \mathrm{H}_{21} \mathrm{O} 6$ & $345 \cdot 37 \mathrm{~g} / \mathrm{mol}$ & 6 & o & Yes; o violation & 2.06 \\
\hline 3-(1-Naphthoyl)benzoate & $\mathrm{C}_{1} 8 \mathrm{H}_{11} \mathrm{O}_{3}$ & $275.28 \mathrm{~g} / \mathrm{mol}$ & 3 & o & Yes; o violation & 3.26 \\
\hline 2-Hydroxy-3-oxoicosanoate & $\mathrm{C}_{2} \mathrm{OH}_{37} \mathrm{O}_{4}$ & $341.51 \mathrm{~g} / \mathrm{mol}$ & 4 & 1 & Yes; o violation & $3 \cdot 30$ \\
\hline $\begin{array}{l}\text { (4-Cinnamoyl-3,5-dihydroxyphenoxy) } \\
\text { acetate }\end{array}$ & $\mathrm{C}_{17} \mathrm{H}_{13} \mathrm{O} 6$ & $313.28 \mathrm{~g} / \mathrm{mol}$ & 6 & 2 & Yes; o violation & 1.17 \\
\hline
\end{tabular}

Several compounds failed in ADMET analysis. For drug discovery, many guiding principles and rules were made to analyze the physicochemical properties. The first and the most important rule was the rule of 5 which was discovered by Lipinski in 1997. The rule of five states that all the compounds are supposed to follow these five criteria so that they are membrane penetrable and have passive diffusion in the human intestine. The five criteria were $\log \mathrm{P}<5$; Molecular weight $(\mathrm{MW}) \leq 500$; hydrogen bond acceptor $(\mathrm{HBA}) \leq 10$; hydrogen bond donor (HBD) $\leq 5$ and no. of rotatable bond $\geq$ 10. Few phytocompounds have a molecular weight of more than 500, violation in MW can impact the changes in molecular events such as blood brain barrier penetration, absorp- tion and metabolism, and hard to get penetrated in the human body. Some phytocompounds have HBA and HBD higher violating Lipinski rule, both the considerations enhance the bioavailability and permeability of the drug. An increase in HBD can lead to poor penetration and bioavailability. It was also found that some phytocompounds have a high value of $\log \mathrm{p}$ and some have a low value of $\log \mathrm{p}$. Lipophilicity $\log$ $P$ should be less than or equal to 5 . If there is a high value of $\log \mathrm{p}$ solubility and metabolism get affected whereas the low value of $\log p$ results in decreased permeability. Highly hydrophilic compounds cannot enter the membrane because they are not capable of penetrating the hydrophobic part of the bilayer membrane whereas highly lipophilic get trapped 
in the membrane. During ADMET analysis distribution of phytocompounds as a drug in the human body was also monitored which include blood brain barrier (BBB) penetration, central nervous system (CNS), and P-glycoprotein (P-gp) efflux. Toxicity caused by drug-drug interaction (DDI) ${ }^{20,21}$ is always a major concern. CYP enzymes family is the proteins that plays the important role in DDI and also regulate the drug metabolism and the server ProTox-II was also used, which provides the toxicity of the phytocomponds LD50 in $\mathrm{mg} / \mathrm{kg}$. This server classifies the toxicity of a compound in 6 different classes. All the compounds qualified the ADMET analysis mainly falls under class 5 and 6 . In class 5 LD50 is greater than in 2000 but less than 5000 which means it may be harmful if used and in class 6 LD50 is greater than 5000 which means it is nontoxic ${ }^{16}$. The phytocompounds which pass all the ADMET analysis further docked with the target. In the ADMET analysis the phytocompounds Cholic acid, Diffractaic acid, 3,3-Bis(3,4-dimethoxyphenyl)propanoate, 3-(1-Naphthoyl)benzoate, 2-Hydroxy-3-oxoicosanoate, (4-Cinnamoyl-3,5-dihydroxyphenoxy)acetate, re-found to qualify the ADMET analysis and further docked with the target. 8 phytocompounds of Tinospora cordifolia docked with 5YIO_A. Docking analysis was executed by using HEX software. HEX works in FFT algorithm Fast Fourier Transform (FFT) and the docking energy of the 2-Hydroxy-3-oxoicosanoate with ATP synthase displayed the best docking as it shows the least binding energy i.e. -320.27 when compared with the bedaquiline i.e - 288.75 . The docking energy of various compounds is tabulated in table 4 .

Table 4: Docking Energy of all the phytocompounds
and Bedaquiline
\begin{tabular}{|llll|}
\hline ID & Phytocompounds Name & Etotal & Eshape \\
4534966 & Bedaquiline & -288.75 & -288.75 \\
192176 & Cholic acid & -280.82 & -280.82 \\
85597 & Diffractaic acid & -266.72 & -266.72 \\
4316406 & $\begin{array}{l}\text { 3,3-Bis(3,4-dimethoxyphe- } \\
\text { nyl)propanoate }\end{array}$ & -246.02 & -246.02 \\
5320699 & 3-(1-Naphthoyl)benzoate & -247.06 & -247.06 \\
13902409 & 2-Hydroxy-3-oxoicosanoate & -320.27 & -320.27 \\
5461627 & $\begin{array}{l}\text { (4-Cinnamoyl-3,5-dihy- } \\
\text { droxyphenoxy)acetate }\end{array}$ & -263.32 & -263.32 \\
\hline
\end{tabular}

PyMol and LigPlot+ give the visualization of the docking which is shown in figure 2. It helps in proper visualization of the attraction between the ligand and receptor. PyMol shows the $3 \mathrm{D}$ visualization of the ligand and receptor whereas LigPlot + shows the 2D intermolecular binding of the ligand with 105 ARG amino acid of the receptor. The study showed that 2-Hydroxy-3-oxoicosanoate can be a powerful inhibitor of Mtb F-ATP synthase subunit epsilon (ATPE) (PDB file:
5YIO). This study was done based on in silico tools and can be further validated in the wet lab.

\section{CONCLUSION}

Mtb bacteria are always being a challenge due to its MultiDrug Resistant(MDR) and Extensive Drug Resistance(XDR) property. Bedaquiline drug is used against Mtb but recently many cases are reported globally showing resistance towards bedaquline, so the urge of new drug discovery came into projection. In the current study, all the phytocompounds of $T i$ nospora cordifolia is been identified and analyzed to be used as a drug against a target $5 \mathrm{YIO}$ protein present in Mtb. Many of the phytocompounds show good ADMET analysis and docking results. Among all the phytocompounds 2-Hydroxy3-oxoicosanoate shows the best result in terms of docking. This study can be validated further in the wet lab and can be a potential drug for the treatment of Tuberculosis.

\section{ACKNOWLEDGEMENT}

The authors express the deep sense of gratitude to the Department of Biotechnology of Graphic Era Deemed to be University for all the support, assistance, and constant encouragements to carry out this work.

\section{Conflicts of Interest}

All authors have none to declare.

\section{REFERENCES}

1. Mase S, Chorba T, Lobue P, Castro K. Provisional CDC guidelines for the use and safety monitoring of bedaquiline fumarate (Sirturo) for the treatment of multidrug-resistant tuberculosis. Morbidity and Mortality Weekly Report: Recommendations and Reports. 2013 Oct 25;62(9):1-2.

2. World Health Organization. Global tuberculosis report 2018.

3. Shahbaaz M, Cloete R, Grobbelaar M, Sampson S, Christoffels A. Structure based identification of novel inhibitors against ATP synthase of Mycobacterium tuberculosis: A combined in silico and in vitro study. Int J Bio Macromol 2019;135:582-590.

4. Lu P, Lill H, Bald D. ATP synthase in mycobacteria: special features and implications for a function as drug target. Biochim Biophys Acta 2014;1837(7):1208-1218.

5. Nguyen TV, Anthony RM, Bañuls AL, Nguyen TV, Vu DH, Alffenaar JW. Bedaquiline resistance: its emergence, mechanism, and prevention. Clin Infect Dis 2018;66(10):1625-1630.

6. Sharifi-Rad J, Salehi B, Stojanović-Radić ZZ, Fokou PV, Sharifi-Rad M, Mahady GB, et al. Medicinal plants used in the treatment of tuberculosis-Ethnobotanical and ethnopharmacological approaches. Biotech Adv 2020:107629.

7. Kim S, Thiessen PA, Bolton EE, Chen J, Fu G, Gindulyte A, et al. PubChem substance and compound databases. Nucleic Acids Res 2016;44(D1):D1202-1213.

8. Sonkamble VV, Kamble LH. Antidiabetic potential and identification of phytochemicals from Tinospora cordifolia. Am J Phytomed Clin Therapeu 2015;3(1):097-110. 
9. Berman HM, Westbrook J, Feng Z, Gilliland G, Bhat TN, Weissig $\mathrm{H}$, et al. The protein data bank. Nucleic Acids Res 2000;28(1):235-242.

10. Joon S, Ragunathan P, Sundararaman L, Nartey W, Kundu S, Manimekalai MS, et al. The NMR solution structure of Mycobacterium tuberculosis F-ATP synthase subunit $\varepsilon$ provides new insight into energy coupling inside the rotary engine. The FEBS journal. 2018;285(6):1111-1128.

11. Binkowski TA, Naghibzadeh S, Liang J. CASTp: computed atlas of surface topography of proteins. Nucleic Acids Res 2003;31(13):3352-3355.

12. Kim S, Thiessen PA, Bolton EE, Chen J, Fu G, Gindulyte A, et al. PubChem substance and compound databases. Nucleic Acids Res 2016;44(D1):D1202-1213.

13. Pence HE, Williams A. ChemSpider: An online chemical information resource. J Chem Educ 2010,87(11):1123-1124.

14. O'Boyle NM, Banck M, James CA, Morley C, Vandermeersch T, Hutchison GR. Open Babel: An open chemical toolbox. J Cheminformatics 2011;3(1):33.

15. Daina A, Michielin O, Zoete V. SwissADME: a free web tool to evaluate pharmacokinetics, drug-likeness and me- dicinal chemistry friendliness of small molecules. Sci Rep 2017;7:42717.

16. Banerjee P, Eckert AO, Schrey AK, Preissner R. ProTox-II: a webserver for the prediction of toxicity of chemicals. Nucleic Acids Res 2018;46(W1):W257-263.

17. Ritchie D, Orpailleur T. Hex 8.0. 0 User Manual. Protein Docking Using Spherical Polar Fourier Correlations Copyright c. 1996;2013.

18. Mooers BH. Simplifying and enhancing the use of PyMOL with horizontal scripts. Protein Sci 2016;25(10):1873-1882.

19. Wallace AC, Laskowski RA, Thornton JM. LIGPLOT: a program to generate schematic diagrams of protein-ligand interactions. Protein Eng 1995;8(2):127-134.

20. Lagorce D, Bouslama L, Becot J, Miteva MA, Villoutreix BO. FAF-Drugs4: free ADME-tox filtering computations for chemical biology and early stages drug discovery. Bioinformatics 2017;33(22):3658-3660.

21. Lagorce D, Douguet D, Miteva MA, Villoutreix BO. Computational analysis of calculated physicochemical and ADMET properties of protein-protein interaction inhibitors. Sci Rep 2017;7:46277.
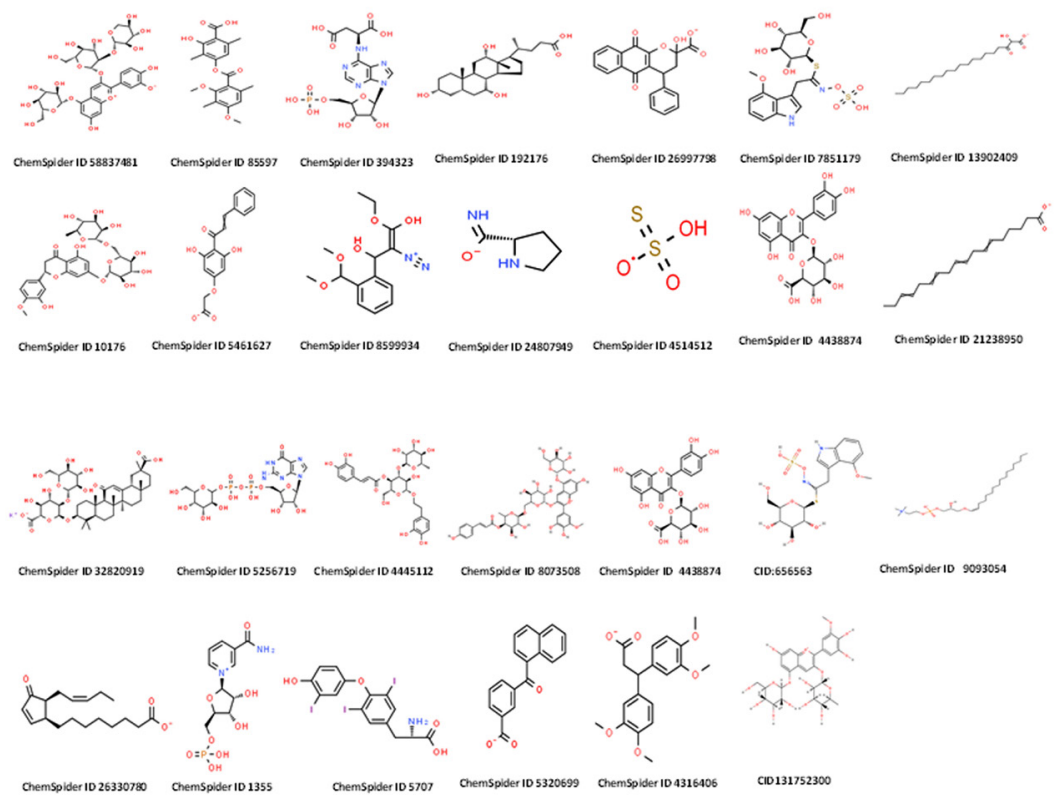

Figure 1: 2D structure of the phytocompounds retrieved from PubChem and ChemSpider.
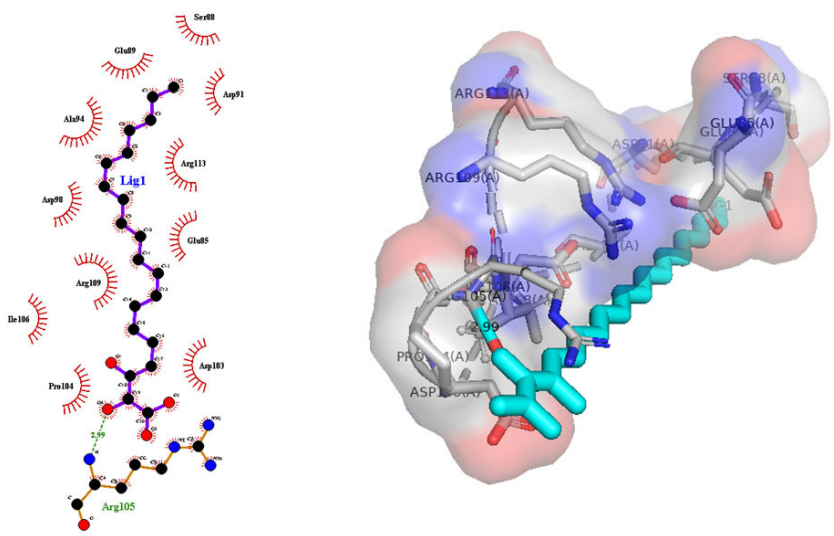

Figure 2: Visualization of docking 5YIO_A with the ligand 2-Hydroxy-3-oxoicosanoat. 